\title{
The Association Between Problem Gambling and Suicidal Ideations and Attempts: A Case Control Study in the General Swedish Population
}

\author{
Kristina Sundqvist ${ }^{1}$ (D) Peter Wennberg ${ }^{2,3}$
}

Accepted: 22 December 2020 / Published online: 25 January 2021

(c) The Author(s) 2021

\begin{abstract}
The association between problem gambling and suicidal behaviours is well established in treatment seeking populations, but less explored among sub-clinical problem gamblers in the general population. The aim of this study was to examine the association between problem gambling (including moderate risk gambling) and suicidal ideations/suicide attempts, in the general Swedish population. Another aim was to compare problem gamblers with and without suicide ideation/attempts. A case-control study nested in the Swelogs cohort was used. Both ideations and attempts were about twice as frequent among the cases compared to the controls. After controlling for socio-economic status and life-time mental health problems, suicidal ideation, but not attempts, remained significantly higher among the cases compared to the controls. The largest difference between attempters and nonattempters were on payment defaults and illicit drug abuse, whereas depression yielded the largest difference between ideators and non-ideators. Problem gambling severity (PGSI $8+$ ) resulted in the smallest difference, compared to the other variables, between attempters and non-attempters. Even though no conclusion regarding the casual relationship can be drawn in this type of study, it seems like sub-clinical levels of problem gambling might have an impact on suicidal ideations whereas for suicide attempts to occur, other factors need to be present. In addition to mental health issues, financial difficulties may be such factors.
\end{abstract}

\section{Introduction}

Gambling is a leisure activity that can progress and have severe consequences. Studies worldwide have found prevalence rates of problem gambling ranging from 0.5 to 7.6 pending on study and cultural settings, with an average across all countries of $2.3 \%$

Kristina Sundqvist

kristina.sundqvist@su.se

1 Department of Psychology, Stockholm University, Stockholm, Sweden

2 Department of Public Health Sciences, Stockholm University, Stockholm, Sweden

3 Department of Global Public Health, Karolinska Institutet, Solna, Sweden 
(Williams et al. 2012). Problematic gambling has been associated with other psychiatric conditions, criminality and even suicide (Lorains et al. 2011).

There are several terms for excessive gambling behavior. In the Diagnostic and Statistical Manual of Mental Disorders, 'gambling disorder' is used to describe severe gambling problems (5th ed; DSM-5; American Psychiatric Association 2013). However, the broader term problem gambling, used in this study, is often used to include those that do not fill the criteria's for a diagnosis but still suffer significant consequences from their gambling (Blaszczynski and Nower 2002). Suicidal behavior can be thought of as existing on a spectrum (World Health Organization 2014), including self-harm, ideations (thoughts, wishes and plan of taking one's own life) and actual suicidal attempts. Recent developments in suicide theory and research have proposed the 'ideation-toaction framework', which suggests that the development of suicidal ideation and the progression from ideation to suicide attempts are distinct phenomena with diverse etiology (Klonsky et al. 2016).

Previous research on clinical samples has identified a link between problem gambling and both suicidal ideations (thoughts, wishes and plans) and attempts (Moghaddam et al. 2015). As negative consequences and losses grow, suicide may be seen as the only solution to both financial and psychological stress (Hodgins et al. 2006). Studies involving treatment-seeking problem gamblers have shown that $36 \%$ to $50 \%$ had a history of suicidal ideation (Battersby et al. 2006; Lejoyeux et al. 2002; Petry and Kiluk 2002), and 20\% to 30\% of problem gamblers had made suicide attempts (Guillou-Landreat et al. 2016; Thompson and Schwer 2005). A register based study in Sweden showed a 15-fold increase in suicide mortality for individuals 20-74 years old diagnosed within the health care system with gambling disorder, compared to the general population (Karlsson and Håkansson 2018). In a case-control study it was found that both suicide attempts and ideations were over 10 times more common among the cases (diagnosed with gambling disorder) compared to their controls (Black et al. 2015). In addition, disorders commonly comorbid with problem gambling, such as mood and substance use disorders are also associated with suicide (Windfuhr and Kapur 2011), thereby further increasing an individual's vulnerability for suicidal ideation and/or attempts. A recent study found that even though Suicidal behavior were common in patients with problem gambling, it was markedly more common in the presence of other comorbid disorders (Håkansson et al. 2020).

Studies on the relationship between gambling and suicide in the general population are rare. This is unfortunate since treatment seeking samples are unrepresentative due to selection bias and hence differ from problem gamblers in the general population. Studies suggests that clinical samples mainly comprise of white, middle-aged gamblers (Volberg 1994), with more severe problem gambling symptoms and are more likely to have experienced comorbid conditions (Lorains et al. 2011). A study by Hodgins et. al. (2006) revealed that suicide attempts among a community sample of problem gamblers were nearly universally made when participants reported feeling depressed, and that suicidal ideations predated problem gambling onset with about ten years. Additionally, more than half of these respondents reported that the majority of their suicide attempts had been made under the influence of alcohol or other drugs. In another Canadian study, the association between problem gambling and suicide ceased to be statistically significant when additional mental disorders were included in the analysis (Newman and Thompson 2003). It was concluded in this study that the association between gambling and suicide attempts may be due to the common factor of mental illness. However, this contradicts another Canadian study (Newman and Thompson 2007), where suicidality was significantly associated with problem gambling, despite adjustment for other sociodemographic and psychiatric variables. 
Studies exploring confounding factors have found problem gambling severity, being in depth, high financial losses, mood disorders, alcohol/substance use disorders and female gender to affect the association between problem gambling and suicidal events (Battersby et al. 2006; Bischof et al. 2016; Manning et al. 2015; Wong et al. 2010). But studies on the roles of those factors are inconclusive. In the study by Bettersby (2006), for example, gender was not significantly associated with suicidal events, and in the study by Bischof (2016), gambling severity was not independently associated with suicidal events. The same study also found EGM gambling to be associated with suicidal events (Bischof et al. 2016).

As described above, treatment seeking samples most likely differ from communitybased samples, for instance in terms of problem gambling severity and other co-occurring psychiatric conditions. The association among problem gambling and suicidality is less explored within community-based samples compared to treatment seeking samples, as well as among sub-clinical samples.

The aim of this study was to examine the association between problem gambling and suicidal ideations, as well as the association between problem gambling and suicide attempts, in the general population.

A second aim was to explore other factors possibly contributing to the associations by comparing problem gamblers with and without suicidal ideations/attempts.

\section{Methods}

\section{Design}

The Swedish longitudinal gambling study (Swelogs), is a research program on gambling and problem gambling in Sweden, initiated in 2008 and managed by the Public Health Agency of Sweden (Romild et al. 2014; The Public Health Agency of Sweden 2013). Swelogs includes two data sets called the Epidemiological track (EP) and the In-Depth (ID) track. The EP-track consisted of a stratified random sample of 15,000 individuals (the procedure is decribed in detail by Romild et al. 2014). The ID-track is a case-control study nested in the Swelogs cohort. Details about the data collection has been previously described (Fröberg 2015; Sundqvist and Rosendahl 2019), and will be described briefly below.

The purpose of the ID track is to collect information about the mental health of the study participants in a lifetime perspective. Caseness was defined by scoring 3 or more on PGSI 12 months or on SOGS-R life $(n=591)$. The controls $(n=2400)$ were frequency matched to the cases based on sex and age, with a case/control ratio of 1:3. Two data collections have been carried out within the Swelogs ID track (ID1 and ID2; 2011 and 2013). In addition, a qualitative study was conducted (Samuelsson et al. 2018). Data was collected through telephone interviews conducted by the Centre for Psychiatry Research at Karolinska Institutet, and through postal questionnaires among non-participants in the interview. The interviews covered gambling related issues, a psychiatric diagnostic assessment, life stressors and adverse events, family and participant socio-demographic aspects. Socio-demographic information from official registers was linked to the data set. The measures will be described in more detail in the Methods section. 


\section{Participants}

For the present study, participants from ID1 (2011) was used, since life-time measures was not used in ID2. The sample consisted of 427 cases (34\% female) and 1583 controls ( $35 \%$ female). See Table 1 for participant characteristics.

\section{Measures}

\section{Mental Health and Suicidality}

Mental health (anxiety, depression and substance use) was measured using subscales from the diagnostic instrument Mini International Neuropsychiatric Interview 6.0 (MINI; Sheehan et al. 1998). MINI has been validated in several cultural settings and the test re-test reliability of the subscales of relevance have been found to range from 0.76 to 0.93 (Lecrubier et al. 1997). The questions have the response alternatives yes or no, and interviewers follow a manual for assessment. Most questions in MINI concern current issues, therefore, to be able to assess lifetime problems this time frame was added to the questions. Generalized anxiety disorder, panic disorder, social phobia and post-traumatic stress disorder were combined into 'anxiety disorders'. The information about diagnoses were combined into dichotomous variables (never/ever).

Suicidal ideations and attempts were measured using the suicide questions in the depression subscale. Since those questions were only asked to participants endorsing the criteria for depression, three additional questions about lifetime suicidal thoughts, wishes and plans was added. Those three questions were only asked to participants not answering the original questions regarding suicide in MINI.

Respondents with both previous and current depression were asked if they during at least two weeks did:

Table 1 Characteristics of cases and controls. Odds ratios and 95\% confidence intervals

\begin{tabular}{lllll}
\hline & $\begin{array}{l}\text { Case } \% \\
\mathrm{n}=427\end{array}$ & $\begin{array}{l}\text { Control \% } \\
\mathrm{n}=1583\end{array}$ & OR & 95\% CI \\
\hline Matching variables & & & & \\
Gender F/M & $35 / 65$ & $34 / 66$ & & \\
Age M (SD) & $28.2(13.7)$ & $28.1(14.7)$ & & \\
Other sample characteristics & & & & \\
SES (low vs high) & 27 & 20 & 1.7 & $1.2-2.2$ \\
$\quad$ Low & 44 & 45 & & \\
Medium & 28 & 35 & 2.0 & $1.5-2.5$ \\
High & 33.3 & 20.2 & 1.9 & $1.4-2.5$ \\
Any depression & 24 & 15 & 2.8 & $2.1-3.6$ \\
Any anxiety & 34.3 & 15.9 & 2.2 & $1.3-3.5$ \\
Any alcohol Dependence & 7.7 & 3.7 & & \\
Any Illicit Drug Use & & &
\end{tabular}


- Think about suicide

- Wish they were dead

- Have a suicide plan or

- Make a suicide attempt.

A positive response to any of the three first questions defined the concept suicidal ideations.

The following questions were asked participants with no previous or current depressive episodes (giving 8 of 75 attempts, and 55 of 312 with ideations only), and hence not asked the suicide-related questions connected to those episodes.

During your life-time, have you ever:

- During two weeks or longer, felt that you wanted to die?

- Felt so blue that you considered taking your own life?

- Made a suicide attempt?

A positive response to one of the first two questions was defined as suicidal ideations. Participants endorsing any of the questions on suicidal ideations were categorized as 'ideators', and participants endorsing the question on suicide attempts were categorized as 'attempters'.

\section{Gambling}

Swelogs includes two gambling measures: The South Oaks Gambling Screen-Revised Life Time measure (SOGS-R Life) and the Problem Gambling Severity Index (PGSI; Ferris and Wynne 2001). The SOGS was developed to use in clinical settings among adults (Lesieur and Blume 1987). In Swelogs, the SOGS-R was included to enable comparisons with previous studies that have used the instrument, and because it includes life-time problem gambling, which other instruments often do not. The psychometric properties of the instrument have been evaluated with satisfactory results; test re-test reliability $0.71-0.74$ and internal consistency 0.97 (Lesieur and Blume 1987; Stinchfield 2002). SOGS-R consists of 21 items, of which 20 dichotomous items adds up into a summary score of 0-20 points. To measure problem gambling in the past twelve months the PGSI was used and it was administered to respondents who had reported any gambling in the past twelve months. The PGSI was developed to measure problem gambling in the general population from a public health perspective, focusing on harm and consequences (Ferris and Wynne 2001). Studies have shown that the PGSI have high internal reliability; 0.85 (Holtgraves 2009; Orford et al. 2010). PGSI consists of 9 items with response alternatives from never to almost always (0-3 points per item), with a maximum score of 27 points. It is recommended that, based on the sum-score, respondents are categorized into: non-problem gambling (0), low-risk gambling (1-2), moderate risk gambling (3-7), and problem gambling (8+) (Ferris and Wynne 2001). In practice, to increase statistical power the categories problem gambling and moderate risk gambling are often collapsed to one. In the Swelogs project, as well as in this study, the categories with a score of 3-7 and 8-27 was collapsed to one category, problem gambling. 


\section{Other Measures: Socio-Economic Status}

Socio-demographic information was gathered from official national registers. The variable socio-economic status was based on educational level and was categorized as follows; low SES-primary or lower secondary school, medium SES-upper secondary school and high SES-post-secondary or tertiary school.

\section{Response Rate and Attrition}

During fall 2011, 1876 interviews were conducted, giving a response rate of $78.2 \%$. A larger proportion of the controls responded, compared to the cases (87.5\% versus $72.3 \%$ ). There were no differences in response rate across gender.

\section{Analyses}

Cases and controls were compared regarding suicidal ideations and attempts using Chisquare tests. Logistic regression was used to examine the association between lifetime problem gambling and suicidality. To check for multicollinearity, Variance Inflation Factors (VIF) were calculated through linear Regression (Midi et al. 2010) where all variables were included. All VIF-scores were between 1.0 and 1.2 and multicollinearity is therefore not likely to be a problem. Separate analyses were conducted with attempts and ideations (excluding attempters) as dependent variables. Variables known in previous research (Borges and Loera 2010; Franklin et al. 2017; Hawton et al. 2013; Hodgins et al. 2011; Sareen et al. 2005; van der Maas 2016) to be associated with both problem gambling and suicidal events, and admitted for in the Swelogs ID-track, were chosen as confounding variables in the analyses (socio-economic status, alcohol dependence, illicit drug abuse, depression and anxiety). The crude model shows the overall association between problem gambling and suicidal thoughts/attempts. Model 1 was adjusted for socio-economic status. Model 2 was adjusted for socio-economic status, alcohol dependence and illicit drug abuse. Finally, life-time depression and anxiety were added in Model 3. Data was analyzed using IBM SPSS statistics 24.

Since the cases and controls in this study were matched based on age and gender, those variables were not included in the models. Using logistic regression, sensitivity analyses conducted including those variables did not show any significant effect on the overall association between problem gambling and suicidal attempts/ideations. Lifetime measures was used for all psychiatric conditions. Sensitivity analyses was conducted including present psychiatric conditions, as well as lifetime alcohol misuse and lifetime illicit drug use dependence. However, they did not affect the models and were therefore not included.

As common in case-control studies, associations (in this case between problem gambling and suicidality) were estimated using odds ratios. Since case-control studies are typically done when the study outcome is uncommon in the population, odds ratios will approximate risk ratios (Kelsey et al. 1996; MacMahon and Pugh 1970).

Finally, gamblers with and without suicidal behaviours were compared with regard to the above variables using Chi-square tests. Since we hypothesized, based on previous research that financial difficulties might discriminate attempters from non-attempters (Meltzer et al. 2011; Richardson et al. 2013), payment defaults was added in this analysis. 


\section{Results}

Suicidal attempts were twice as common among the cases (6.6\%) compared to the controls $(3.3 \%)$ Chi-square $=9.0(1), p=0.003$. Suicidal ideations (attempters excluded) was almost twice as common among the cases $(21.2 \%)$ compared to the controls (11.2\%), Chisquare $=25.2(1), p=<0.001$.

In the first set of binary logistic regression models, the association between life-time problem gambling and life-time suicidal attempts was examined (controls $=$ ref). As shown in Table 2 there was a bivariate association between problem gambling and suicidal attempts. This association remained significant when controlling for socio-economic status. However, when also controlling for alcohol dependence and illicit drug abuse, the association between problem gambling and suicidal attempts ceased to be significant. Lifetime illicit drug abuse, and lifetime depression had the strongest impact on the association.

In the second set of binary logistic regression models, the association between problem gambling and suicidal ideations was studied (see Table 2). Like with suicidal attempts, the risk for having had suicidal ideations were more than double for the cases compared to the controls, and the association remained significant after controlling for socio-economic status. As opposed to the models on suicidal attempts, the association between problem gambling and suicidal ideations remained significant after controlling for lifetime alcohol

Table 2 Comparison between cases and controls regarding the association between problem gambling and: 1. suicide attempts and 2. suicidal ideations $(\mathrm{N}=1859)$

\begin{tabular}{|c|c|c|c|c|}
\hline & $\begin{array}{l}\text { Crude Model } \\
\text { OR (CI 95\%) }\end{array}$ & $\begin{array}{l}\text { Model } 1 \\
\text { OR (CI 95\%) }\end{array}$ & $\begin{array}{l}\text { Model } 2 \\
\text { OR (CI 95\%) }\end{array}$ & $\begin{array}{l}\text { Model } 3 \\
\text { OR (CI 95\%) }\end{array}$ \\
\hline \multicolumn{5}{|l|}{$\begin{array}{l}\text { 1. Attempts } \\
(\mathrm{n}=74)\end{array}$} \\
\hline Problem gambling (controls ref) & $2.1(1.3-3.4)$ & $2.1(1.2-3.4)$ & $1.6(0.9-2.8)$ & $1.2(0.7-2.2)$ \\
\hline SES low vs high (ref) & & $2.6(1.4-5.0)$ & $2.5(1.3-4.8)$ & $2.2(1.1-4.4)$ \\
\hline Alcohol dependence & & & $2.5(1.3-5.0)$ & $1.7(0.8-3.6)$ \\
\hline Illicit drug abuse & & & $6.8(3.2-14.3)$ & $4.1(1.8-9.4)$ \\
\hline Anxiety & & & & $2.5(1.4-4.3)$ \\
\hline Depression & & & & $11.0(5.3-22.8)$ \\
\hline \multicolumn{5}{|l|}{$\begin{array}{l}\text { 2. Ideations } \\
(\mathrm{n}=228)\end{array}$} \\
\hline $\begin{array}{l}\text { Problem gambling (controls ref) } \\
\text { (controls = ref) }\end{array}$ & $2.1(1.6-2.8)$ & $2.2(1.6-2.9)$ & $1.9(1.4-2.6)$ & $1.5(1.1-2.1)$ \\
\hline SES low vs. high (ref) & & $1.7(1.2-2.3)$ & $1.6(1.2-2.3)$ & $1.6(1.1-2.4)$ \\
\hline Alcohol dependence & & & $1.9(1.3-2.9)$ & $1.4(0.9-2.2)$ \\
\hline Illicit drug abuse & & & $4.5(2.6-7.8)$ & $3.2(1.7-6.0)$ \\
\hline Anxiety & & & & $2.3(1.6-3.2)$ \\
\hline Depression & & & & $7.3(5.3-9.9)$ \\
\hline
\end{tabular}

Crude Model: Unadjusted

Model 1: Adjusted for socio-economic status (SES)

Model 2: Adjusted for socio-economic status (SES), lifetime alcohol dependence and lifetime illicit drug abuse

Model 3: Adjusted for socio-economic status (SES), lifetime alcohol dependence, lifetime illicit drug abuse, lifetime anxiety and depression 
dependence and illicit drug abuse. The association also remained significant in the full model, when lifetime anxiety and depression was added.

In sum, problem gambling seems to be directly associated with suicidal ideations, but not with suicide attempts, after controlling for other psychiatric conditions.

Finally, problem gamblers (the cases) with and without lifetime suicide attempts/ideations were compared. As shown in Table 3, attempters differed significantly on all variables, except problem gambling severity, compared to non-attempters. More attempters, compared to non-attempters, had low socio-economic status, had payment defaults, and had suffered from alcohol dependence, illicit drug abuse, anxiety and depression.

The same pattern was found among participants with previous suicidal ideations (but no actual attempts) compared no non-ideators, however only anxiety and depression and payment defaults differed significantly.

Interestingly, having had payment defaults was almost four times as common among attempters compare to non-attempters. Also, lifetime illicit drug abuse were more than four times as prevalent among the attempters. Gambling severity (PGSI 8+), was the factor that yielded the smallest difference between attempters and non-attempters. For ideators, the largest difference compared to non-ideators were on lifetime depression, whereas alcohol dependence generated the smallest difference.

\section{Discussion}

In this study, the associations between problem gambling and suicidal ideations/attempts was examined using a case control design with a sample from the general Swedish population. Both ideations and attempts were about twice as frequent among the cases compared to the controls. After controlling for socio-economic status and life-time mental health problems, rates of lifetime suicidal ideation (thoughts and plans) was significantly higher among the cases compared to the controls. The association between problem gambling and lifetime attempts ceased to be statistically significant when employing the same covariates as mentioned above.

When comparing cases with and without suicide attempts/ideations, the largest difference between attempters and non-attempters were on payment defaults and illicit drug abuse, whereas depression yielded the largest difference between ideators and non-ideators. Problem gambling severity (PGSI 8+) resulted in the smallest difference, compared to the other variables, between attempters and non-attempters.

The results from this study suggests (even thought there were small differences) that problem gambling on its own may have an effect on suicidal ideations, whereas for an actual suicide attempt to happen, additional factors might be needed. Financial difficulties and illicit drug abuse were such factors that might have played that role among the cases in this study.

The findings from this study are in line with the findings from the study by Thomsson and Newman (2005), where the association between problem gambling and suicide attempts ceased to be statistically significant after controlling for mental illness. On the other hand, in our sample, problem gambling was associated with suicidal ideations even when considering other psychiatric conditions.

The association between problem gambling and suicidal behavior (ideations and attempts) were weaker in this study than in some previous works (Battersby et al. 2006; Newman and Thompson 2007; Petry and Kiluk 2002) and this might be due to the 


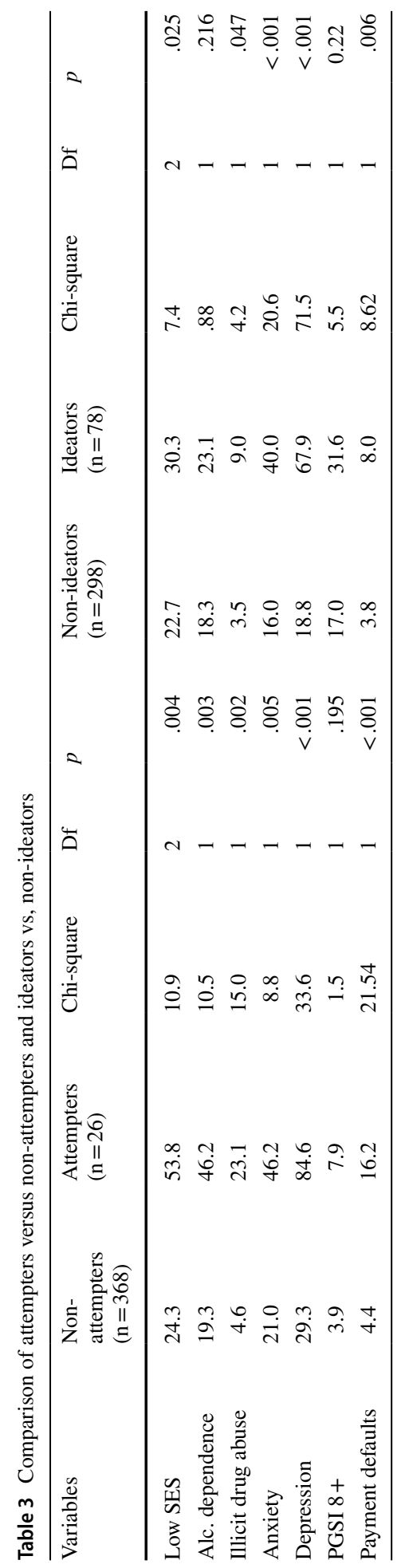


non-clinical sample from the general population, as well as the low threshold for problem gambling used in this study.

The finding that even sub-clinical levels of problematic gambling also seem to increase the risk of suicidal ideations is important information that ads to the existing literature. This fact, that the groups of predominantly subclinical gamblers in this study showed an increased risk of suicidal ideations emphasize that risk gambling and problem gambling that does not fulfill the requisites for a diagnosis also deserves special attention from a preventive perspective.

Having said that, it seems that mild problem gambling per se might not be enough for progressing from suicidal ideations to actual attempts unless combined with other psychiatric comorbidity such as depression or substance use problems, or other factors such as financial difficulties. On the other hand, it is well known than the co-occurrence of psychiatric comorbidity is high among problem gamblers (Lorains et al. 2011). Especially substance use disorders, depression and anxiety disorders are commonly found in problem gamblers, with a prevalence rate of about $58 \%, 38 \%$ and $37 \%$ respectively. With that in mind, when clinicians meet problem gamblers, suicide ideations and previous attempts should be explored.

A major strength in this study is the use of a sample from the general population, which generates more generalizable results compared to results from studies using treatment seeking samples. Another strength is that psychiatric diagnoses were based on clinical interviews rather than self-assessment measures. Yet another strength is the inclusion of problem gamblers ranging in severity from mild to severe, mirroring the actual gambling situation in society. In addition, the distinction between suicidal ideations and attempts make it possible to find divergent patterns.

Some of the psychiatric factors used as covariates in this study are reciprocally interwoven. Hence, establishing causality in this type of study is certainly difficult. Our analyses are based on some assumptions regarding causality. For instance, we assume that mental health issues precede suicidal behaviors. Some previous research seem to confirm this (Miché et al. 2018; Sundqvist and Rosendahl 2019). Having said that, the mental health variables refer to lifetime problems, which makes it impossible to pinpoint these events in time, which is a limitation of the study.

More of the risk factors that lead to suicidal ideations does not necessarily lead to suicidal attempts. Instead, progression from suicidal ideations to attempts might require additional factors. Hence, a suggestion for future research concern factors that discriminate between suicidal ideations and suicidal attempts among problem gamblers. Further, the fact that problem gambling, mental health issues and suicidal behaviours appear in different cultural settings, calls for more population-based studies on this topic.

\section{Conclusions}

Problem gambling is associated with suicidal ideations and attempts in the general population, even when including sub-clinical levels of problem gambling. However, the association between problem gambling and suicidal attempts is in part explained by other mental health variables (depression, anxiety, AUD and SUD). Even though no conclusion regarding the casual relationship can be drawn in this type of study, it seems like sub-clinical levels of problem gambling might have an impact on suicidal ideations whereas for suicide 
attempts to occur, other factors need to be present. Payment defaults and illicit drug abuse may be example of such factors.

Acknowledgements We would like to thank Olof Molander for valuable comments on our manuscript.

Funding Open Access funding provided by Stockholm University. This work was conducted within the research programme REGAPS (Responding to and Reducing Gambling Problem Studies). The REGAPS programme is supported by the Swedish Research Council for Health, Working life and Welfare (Forte) under grant 2016-07091. The study was also funded by the Svenska Spel independent research council under grant FO2016-0017.

\section{Compliance with Ethical Standards}

Conflict of interest Peter Wennberg declares that he has no conflict of interest. While Kristina Sundqvist has no current or past direct affiliations with the gambling industry, she has received funding from the Svenska Spel research council. This research council is financed by the state-owned gambling company Svenska Spel.

Ethical approval Ethical approval to conduct the study was obtained from the Regional Ethical Review Board in Sweden (ref. 2017-172-31/5) and were in accordance with the 1964 Helsinki declaration and its later amendments

Open Access This article is licensed under a Creative Commons Attribution 4.0 International License, which permits use, sharing, adaptation, distribution and reproduction in any medium or format, as long as you give appropriate credit to the original author(s) and the source, provide a link to the Creative Commons licence, and indicate if changes were made. The images or other third party material in this article are included in the article's Creative Commons licence, unless indicated otherwise in a credit line to the material. If material is not included in the article's Creative Commons licence and your intended use is not permitted by statutory regulation or exceeds the permitted use, you will need to obtain permission directly from the copyright holder. To view a copy of this licence, visit http://creativecommons.org/licenses/by/4.0/.

\section{References}

American Psychiatric Association. (2013). Diagnostic and statistical manual of mental disorders: DSM5TM (5th ed.). Washington: American Psychiatric Association. https://doi.org/10.1176/appi.books .9780890425596 .

Battersby, M., Tolchard, B., Scurrah, M., \& Thomas, L. (2006). Suicide ideation and behaviour in people with pathological gambling attending a treatment service. International Journal of Mental Health and Addiction, 4(3), 233-246. https://doi.org/10.1007/s11469-006-9022-z.

Bischof, A., Meyer, C., Bischof, G., John, U., Wurst, F., Thon, N., \& Rumpf, H. (2016). Type of gambling as an independent risk factor for suicidal events in pathological gamblers. Psychology of Addictive Behaviors, 30(2), 263-269. https://doi.org/10.1037/adb0000152.

Black, D. W., Coryell, W., Crowe, R., Mccormick, B., Shaw, M., \& Allen, J. (2015). Suicide ideations, suicide attempts, and completed suicide in persons with pathological gambling and their first-degree relatives. Suicide and Life-Threatening Behavior, 45(December), 700-709. https://doi.org/10.1111/ sltb.12162.

Blaszczynski, A., \& Nower, L. (2002). A pathways model of problem and pathological gambling. Addiction, 97(5), 487-499. https://doi.org/10.1046/j.1360-0443.2002.00015.x.

Borges, G., \& Loera, C. R. (2010). Alcohol and drug use in suicidal behaviour. Current Opinion in Psychiatry, 23(3), 195-204. https://doi.org/10.1097/YCO.0b013e3283386322.

Ferris, J., \& Wynne, H. (2001). The Canadian Problem Gambling Index : User Manual. Ottawa, ON: Canadian Centre on Substance Abuse. https://doi.org/10.1007/s10899-010-9224-y.

Franklin, J. C., Ribeiro, J. D., Fox, K. R., Bentley, K. H., Kleiman, E. M., Huang, X., \& Nock, M. K. (2017). Risk factors for suicidal thoughts and behaviors: A meta-analysis of 50 years of research. Psychological Bulletin, 143(2), 187-232. https://doi.org/10.1037/bul0000084. 
Fröberg, F. (2015). Problem gambling among young women and men in Sweden. Stockholm, Sweden: Institutionen för klinisk neurovetenskap/Department of Clinical Neuroscience, Karolinska Institutet.

Guillou-Landreat, M., Guilleux, A., Sauvaget, A., Brisson, L., Leboucher, J., Remaud, M., \& Grall-Bronnec, M. (2016). Factors associated with suicidal risk among a French cohort of problem gamblers seeking treatment. Psychiatry Research, 240, 11-18. https://doi.org/10.1016/j.psychres.2016.04.008.

Håkansson, A., Karlsson, A., \& Nicola, M. D. (2020). Suicide attempt in patients with gambling disorderassociations with comorbidity including substance use disorders. Frontiers in Psychiatry, 11, 1-6. https://doi.org/10.3389/fpsyt.2020.593533.

Hawton, K., Comabella, C. C. I., Haw, C., \& Saunders, K. (2013). Risk factors for suicide in individuals with depression: A systematic review. Journal of Affective Disorders, 147(1-3), 17-28. https://doi. org/10.1016/j.jad.2013.01.004.

Hodgins, D., Mansley, C., \& Thygesen, K. (2006). Risk factors for suicide ideation and attempts among pathological gamblers. American Journal on Addictions, 15(4), 303-310. https://doi.org/10.1080/10550 490600754366.

Hodgins, D. C., Stea, J. N., \& Grant, J. E. (2011). Gambling disorders. The Lancet, 378(9806), $1874-1884$. https://doi.org/10.1016/S0140-6736(10)62185-X.

Holtgraves, T. (2009). Evaluating the Problem Gambling Severity Index. Journal of Gambling Studies, 25(1), 105-120. https://doi.org/10.1007/s10899-008-9107-7.

Karlsson, A., \& Håkansson, A. (2018). Gambling disorder, increased mortality, suicidality, and associated comorbidity: A longitudinal nationwide register study. Journal of Behavioral Addictions, 7(4), 1091-1099. https://doi.org/10.1556/2006.7.2018.112.

Kelsey, J. L., Whittemore, A. S., Evans, A. S., \& Thompson, W. D. (1996). Methods in observational epidemiology (2nd ed.). New York: Oxford University Press.

Klonsky, E. D., May, A. M., \& Saffer, B. Y. (2016). Suicide, suicide attempts, and suicidal ideation. Annual Review of Clinical Psychology, 12, 307-330. https://doi.org/10.1146/annurev-clinp sy-021815-093204.

Lecrubier, Y., Sheehan, D. V., Weiller, E., Amorim, P., Bonora, I., Sheehan, K. H., et al. (1997). The Mini International Neuropsychiatric Interview (MINI). A short diagnostic structured interview: Reliability and validity according to the CIDI. European Psychiatry, 12(5), 224-231. https://doi.org/10.1016/ S0924-9338(97)83296-8.

Lejoyeux, M., Arbaretaz, M., McLoughlin, M., \& Adès, J. (2002). Impulse control disorders and depression. The Journal of Nervous and Mental Disease, 190(5), 310-314. https://doi.org/10.1097/00005 053-200205000-00007.

Lesieur, H. R., \& Blume, S. B. (1987). The South Oaks Gambling Screen (SOGS): A new instrument for the identification of pathological gamblers. American Journal of Psychiatry, 144(9), 1184-1188. https://doi.org/10.1176/ajp.144.9.1184.

Lorains, F. K., Cowlishaw, S., \& Thomas, S. A. (2011). Prevalence of comorbid disorders in problem and pathological gambling: Systematic review and meta-analysis of population surveys. Addiction, 106(3), 490-498. https://doi.org/10.1111/j.1360-0443.2010.03300.x.

MacMahon, B., \& Pugh, T. F. (1970). Epidemiology: principles and methods (1st ed.). Boston: Little, Brown.

Manning, V., Koh, P. K., Yang, Y., Ng, A., Guo, S., Kandasami, G., \& Wong, K. E. (2015). Suicidal ideation and lifetime attempts in substance and gambling disorders. Psychiatry Research, 225(3), 706-709. https://doi.org/10.1016/j.psychres.2014.11.011.

Meltzer, H., Bebbington, P., Brugha, T., Jenkins, R., McManus, S., \& Dennis, M. S. (2011). Personal debt and suicidal ideation. Psychological Medicine, 41(4), 771-778. https://doi.org/10.1017/S0033 291710001261.

Miché, M., Hofer, P. D., Voss, C., Meyer, A. H., Gloster, A. T., Beesdo-Baum, K., \& Lieb, R. (2018). Mental disorders and the risk for the subsequent first suicide attempt: results of a community study on adolescents and young adults. European Child and Adolescent Psychiatry, 27(7), 839-848. https ://doi.org/10.1007/s00787-017-1060-5.

Midi, H., Sarkar, S. K., \& Rana, S. (2010). Collinearity diagnostics of binary logistic regression model. Journal of Interdisciplinary Mathematics, 13(3), 253-267. https://doi.org/10.1080/09720 502.2010.10700699.

Moghaddam, J. F., Yoon, G., Dickerson, D. L., Kim, S. W., \& Westermeyer, J. (2015). Suicidal ideation and suicide attempts in five groups with different severities of gambling: Findings from the National Epidemiologic Survey on Alcohol and Related Conditions. American Journal on Addictions, 24(4), 292-298. https://doi.org/10.1111/ajad.12197. 
Newman, S. C., \& Thompson, A. H. (2003). A population-based study of the association between pathological gambling and attempted suicide. Suicide and Life-Threatening Behavior, 33(1), 80-87. https ://doi.org/10.1521/suli.33.1.80.22785.

Newman, S. C., \& Thompson, A. H. (2007). The association between pathological gambling and attempted suicide: Findings from a national survey in Canada. The Canadian Journal of Psychiatry/ La Revue Canadienne de Psychiatrie, 52(9), 605-612. https://doi.org/10.1007/s00787-017-1060-5.

Orford, J., Wardle, H., Griffiths, M., Sproston, K., Erens, B., Orford, J., \& Erens, B. (2010). PGSI and DSM-IV in the 2007 British Gambling Prevalence Survey : Reliability, item response, factor structure and inter-scale agreement. International Gambling Studies. https://doi.org/10.1080/14459 790903567132.

Petry, N. M., \& Kiluk, B. D. (2002). Suicidal ideation and suicide attempts in treatment-seeking pathological gamblers. The Journal of Nervous and Mental Disease, 190(7), 462. https://doi. org/10.1097/01.NMD.0000022447.27689.96.

Richardson, T., Elliott, P., \& Roberts, R. (2013). The relationship between personal unsecured debt and mental and physical health: A systematic review and meta-analysis. Clinical Psychology Review, 33(8), 1148-1162. https://doi.org/10.1016/j.cpr.2013.08.009.

Romild, U., Volberg, R., \& Abbott, M. (2014). The Swedish Longitudinal Gambling Study (Swelogs): design and methods of the epidemiological (EP-) track. International Journal of Methods in Psychiatric Research, 23(3), 372-386. https://doi.org/10.1002/mpr.1449.

Samuelsson, E., Sundqvist, K., \& Binde, P. (2018). Configurations of gambling change and harm: Qualitative findings from the Swedish longitudinal gambling study (Swelogs). Addiction Research and Theory. https://doi.org/10.1080/16066359.2018.1448390.

Sareen, J., Cox, B. J., Afifi, T. O., de Graaf, R., Asmundson, G. J. G., ten Have, M., \& Stein, M. B. (2005). Anxiety disorders and risk for suicidal ideation and suicide attempts. Archives of General Psychiatry, 62(11), 1249. https://doi.org/10.1001/archpsyc.62.11.1249.

Sheehan, D. V., Lecrubier, Y., Sheehan, K. H., Amorim, P., Janavs, J., Weiller, E., \& Dunbar, G. C. (1998). The Mini-International Neuropsychiatric Interview (MINI): the development and validation of a structured diagnostic psychiatric interview for DSM-IV and ICD-10. The Journal of Clinical Psychiatry, 59(Suppl 20), 22-33.

Stinchfield, R. (2002). Reliability, validity, and classification accuracy of the South Oaks Gambling Screen (SOGS). Addictive Behaviors, 27(1), 1-19. https://doi.org/10.1016/S0306-4603(00)00158-1.

Sundqvist, K., \& Rosendahl, I. (2019). Problem gambling and psychiatric comorbidity-risk and temporal sequencing among women and men: Results from the Swelogs Case-Control Study. Journal of Gambling Studies. https://doi.org/10.1007/s10899-019-09851-2.

The Public Health Agency of Sweden. (2013). Risk-och skyddsfaktorer för problemspelande. Resultat från Swelogs fördjupningsstudie. Retrieved from https://www.folkhalsomyndigheten.se/contentass ets/6d579139d45e43d6ae8e4a053563eedf/risk-skyddsfaktorer-problemspelande.pdf

Thompson, W. N., \& Schwer, R. K. (2005). Beyond the limits of recreation: Social costs of gambling in southern Nevada. Journal of Public Budgeting, Accounting and Financial Management, 17(1), 62. https://doi.org/10.1108/JPBAFM-17-01-2005-B004.

van der Maas, M. (2016). Problem gambling, anxiety and poverty: an examination of the relationship between poor mental health and gambling problems across socio-economic status. International Gambling Studies, 16(2), 281-295. https://doi.org/10.1080/14459795.2016.1172651.

Volberg, R. A. (1994). The prevalence and demographics of pathological gamblers: Implications for public health. American Journal of Public Health, 84(2), 237-241. https://doi.org/10.2105/AJPH.84.2.237.

Williams, R. J., Volberg, R. A., \& Stevens, R. M. G. (2012). The population prevalence of problem gambling: Methodological influences, standardized rates, jurisdictional differences, and worldwide trends. Retrieved from http://www.uleth.ca/dspace/handle/10133/3068

Windfuhr, K., \& Kapur, N. (2011). Suicide and mental illness: A clinical review of 15 years findings from the UK National Confidential Inquiry into Suicide. British Medical Bulletin, 100(1), 101-121. https:// doi.org/10.1093/bmb/ldr042.

Wong, P. W. C., Chan, W. S. C., Conwell, Y., Conner, K. R., \& Yip, P. S. F. (2010). A psychological autopsy study of pathological gamblers who died by suicide. Journal of Affective Disorders, 120(1-3), 213216. https://doi.org/10.1016/j.jad.2009.04.001.

World Health Organization. (2014). Preventing suicide: A global imperative. Geneva. Retrieved December 15, 2020 from http://www.who.int/mental_health/suicide-prevention/world_report_2014/en/.

Publisher's Note Springer Nature remains neutral with regard to jurisdictional claims in published maps and institutional affiliations. 